\title{
LANGUAGE AND SPACE
}

\section{Stephen C. Levinson}

Max Planck Institute for Psycholinguistics, P.O. Box 310, 6500 AH Nijmegen, The Netherlands

KEY WORDS: space, cognition and language, linguistic relativity

\begin{abstract}
This review describes some recent, unexpected findings concerning variation in spatial language across cultures, and places them in the context of the general anthropology of space on the one hand, and theories of spatial cognition in the cognitive sciences on the other. There has been much concern with the symbolism of space in anthropological writings, but little on concepts of space in practical activities. This neglect of everyday spatial notions may be due to unwitting ethnocentrism, the assumption in Western thinking generally that notions of space are universally of a single kind. Recent work shows that systems of spatial reckoning and description can in fact be quite divergent across cultures, linguistic differences correlating with distinct cognitive tendencies. This unexpected cultural variation raises interesting questions concerning the relation between cultural and linguistic concepts and the biological foundations of cognition. It argues for more sophisticated models relating culture and cognition than we currently have available.
\end{abstract}

\section{THE ANTHROPOLOGY OF SPACE AND THE NEGLECT OF “EVERYDAY” SPATIAL CONCEPTS}

The title of this chapter conjoins two of the perduring objects of Western intellectual inquiry: language and space (for historical reviews, see 37, 74). The review focuses on the intersection-the language of space. ${ }^{1}$ Apart from drawing attention to some important new findings about spatial language, it shows how the study of the language of space might play a fundamental role in the anthropology of space more generally.

1 One topic omitted here is "language in space," i.e. the large literature on the distribution of language types and families (see 120 and references therein). For correlations with archaeology, see 135 , and with population genetics, see 22 . 
The use of space, patterns of settlement, and above all, the symbolism of spatial arrangements are classical issues in sociocultural anthropology (36) and archaeology (136). The recent literature on the anthropology of space is now so large that it would resist even book-length review. However, a few inadequate pointers may still be helpful. The traditional focus on cosmological schemes is only somewhat abated by postmodernist scruples about the basis of anthropological knowledge. It is even being resuscitated by ethnoarchaeologists, e.g. in the Mayan culture area where there is an extensive ethnographic literature (see 47 and references therein). Abstract cosmological themes and their instantiation in grandiose architectural schemes, e.g. in the Asian civilizations, are as interesting to archaeologists, architects, and geographers (154) as to ethnographers (151). A related traditional focus on the symbolism of domestic space, with classics such as Bourdieu (8:90), Hugh-Jones (70), Littlejohn (109), and Tambiah (151:176ff), also continues to flourish, but now with much closer documentation $(45,163)$, and a concern with social identity, such as with gender and access $(2,115)$. The anthropology of the "built environment" has received its own excellent review in the current format (92). A new line here is the study of the interactional use of domestic and public spaces, where the homology between linguistic forms and spatial arrangements is beginning to be explored, especially with respect to formal/informal speech registers $(35,81,154,174)$. This line of work, unusually rich in its study of crossmodal symbolism, builds of course on kinesics and interaction analysis (49, 85).

Another traditional line giving birth to new offspring is the spatial mapping of the nature-culture dichotomy, with a new interest in landscape and its associations and symbolism, a development to be found in both sociocultural anthropology (69) and archaeology (152). Landscape in turn ties in to the thriving field of ethnoecology (see 34, 172). All these themes are so well-woven into current anthropological thinking that it is hard to find a good contemporary ethnography that does not dwell at length on spatial matters, although it is much more unusual to find careful attention paid also to spatial language (as in 164).

These references are no more than inadequate bibliographical leads to a vast literature, but one that although multifaceted, has a fundamental gap. The focus has been on collective representations, on cosmologies and the symbolic uses and associations of space, with little mention of the kind of notions in daily use to solve spatial problems (4). One might have expected to find this in the study of hunting or herding and transhumance. Although there are fine studies of navigational lore and practice in the Oceanic world that have sparked much cross-disciplinary interest [see 40, 72; see also Frake's (46) studies of medieval European navigation], this literature stands isolated. There seems to be astonishingly little of substance about how, for example, hunter- 
gatherers find their way in deserts and tundras. Real studies of Australian Aboriginal way-finding appear to reduce to those done by a sailor-explorer $(107,108)$, a seconded Indian policeman (87), and some recent notes by Nash (118).

Another way to study the everyday use of spatial concepts is to investigate the language of spatial description. How do people refer to places, describe spatial arrangements, say where someone is going, and so forth? This is the focus of this review. Even for the anthropologist with relatively little interest in language, this may be a rewarding area, because frequently one can see direct connections between classical questions of cosmology, aesthetics and art style, practical activities like hunting or herding, and the linguistic resources used to make spatial distinctions in different cultures.

Meanwhile, especially in other disciplines, ${ }^{2}$ there has been extensive recent interest in "language and space," with four international conferences within the past year or so. The reasons for the recent concentration of effort are various and include $(a)$ developments within the cognitive sciences, which suggest rich innate bases for spatial cognition of all sorts; $(b)$ a set of expectations from cognitive linguistics, based on assumed commonalities of human experience; $(c)$ a series of "neo-Whorfian" findings within linguistics and psychology that suggest far more cultural variation in spatial language and cognition than expected by either $(a)$ or $(b) .^{3}$

It is this high tension between different orders of "hard facts," e.g. the neuropsychological and the linguistic, as well as between theories of various kinds, that makes the area so interesting. This review tries to lay out the background to this concentration of intellectual activity. ${ }^{4}$

I attempt below to draw attention to the way the new findings in $(c)$ have upset the applecart. But for fear of losing the essentials in the details, I have listed some of the dashed hypotheses and the contradicting findings in advance:

1. Hypothesis: Learning spatial language essentially involves mapping the local expressions onto the antecedently given, largely innate, stock of spatial

2

The disciplines are those that have found common ground under the rubric of the "cognitive sciences," notably philosophy, linguistics, psychology, and the brain sciences. The philosophical literature is hardly referred to here, but see Eilan et al (38) for some papers in the analytical tradition and Casey (21) for the continental tradition.

3 For reconsiderations of the Whorfian issues in general, see Gumperz \& Levinson (51) and Hill \& Mannheim (68). Incidentally, cross-cultural psychologists have, since the time of the Torres Straits expedition at the turn of the century, reported significant cross-cultural variation in spatial acuities. See Berry et al (5).

4

4 The following standard linguistic conventions are employed: Linguistic forms are in italics; when treated as utterances, they are within double quotes. Glosses of actual forms or of a range of forms across languages are in single quotes, while capital letters are employed for hypothetical semantic primes. 
concepts $(24,114,142)$. Thus our cognitive categories determine our linguistic categories.

Contradicting facts: 1. Languages simply do not use the same or even similar spatial concepts (see e.g. 15). 2. Children can be shown to be oriented from their earliest language comprehension to the local culturespecific semantic distinctions (e.g. 23). 3. Where languages encode spatial concepts different from our familiar ones, speakers of those languages can be shown to use correspondingly different spatial concepts in nonlinguistic reasoning; in short, language may determine the cognitive categories rather than the other way around $(18,127)$.

2. Hypothesis: Our conceptions of space are everywhere essentially relativistic and body centered, anthropomorphic and egocentric $(24,114)$. Thus all cultures make symbolic use of the primordial opposition between 'left' and 'right' $(66,119)$.

Contradicting fact: Many languages do not use the planes through the body to derive spatial coordinates, i.e. they have no left/right/front/back spatial terms (e.g. 16, 99). Such cultures may have no symbolic associations with left and right hands (105).

The anthropological contribution to these debates could be massive. Unfortunately the anthropology of space, though rich in its own right, is largely unconnected, a result of the relative neglect of how people think and talk about spatial notions in everyday life. This review therefore concentrates on the low-level, fundamental, everyday spatial notions as discoverable, in both their generalities and cultural specificities, through analyzing language. A central theme is that linguistic patterns point to some systematic differences in the cognitive style with which individuals of different cultures deal with space, and that it is these underlying cognitive specializations that may help us to integrate diverse spatial features within a culture, from cosmology to domestic architecture down to the details of aesthetic preference and material culture. In short, cognition is the intermediate variable that promises to explain cultural propensities in spatial behavior, and language may offer us more than just privileged access to it. It will be helpful then to begin with some brief reference to the picture of spatial cognition offered to us by the cognitive sciences, and return later to the same theme to show how cultural variation needs to be brought into the picture.

\section{SPATIAL COGNITION IN COGNITIVE SCIENCE}

Human beings think spatially. Not exclusively, but it is no doubt one of the fundamental tricks of human cognition. Casting nonspatial problems into spatial thinking gives us literacy, geometry, diagrams, mandala, dream-time landscapes, measures of close and distant relatives and of high and low social 
groups, and much more. Just as maps stand in an abstract spatial relation to real spatial terrain, 5 so spatial arrangements can give us symbolic "maps" to other domains. They can even give us maps of the mind, as exploited in the classical and medieval art of memory (176). From what the cognitive advantage thus accrued derives is not satisfactorily explained, but it is perhaps not fanciful to imagine that it is just another way that ancient brain structures (to do, for example, with navigation) are put to new uses in the extended symbolic world that human beings inhabit.

Spatial cognition has been intensively studied in the twentieth century by sciences as diverse as ethology, cognitive and behaviorist psychology, the study of child development, neurology, and the brain sciences generally. There is for example a wondrous literature on animal way-finding and orientation $(138,162)$, and it is striking how much less is known about human (and primate) cognition and behavior. Nevertheless, the information on human spatial abilities and their neurophysiological basis is enormous, and there is no room here even for the mention of highlights. What is worth drawing attention to is a consistent bias in this research toward a focus on egocentric, anthropomorphic, relativistic spatial concepts and abilities, as opposed to allocentric, abstract, absolute spatial information. The attitude is summed up by Poincaré (133:257): "Absolute space is nonsense, and it is necessary for us to begin by referring space to a system of axes invariably bound to the body."

Take as an example the study of how spatial information is handled in the primate brain. The picture that emerges is one of great complexity, with multiple systems of egocentric coordinates for each sensory mode (125). Thus, when we pick up a coffee cup, the visual system processes the two-dimensional retinal arrays to extract, partly by stereopsis, partly by the analysis of properties of the array itself, a model that includes partial depth information from a particular viewpoint (112). Next we abstract and recognize three-dimensional objects, perhaps by matching them with an inventory of three-dimensional models, thus recognizing the cup and its orientation and placement in depth from the retina. This information then drives the reaching mechanism, first through shoulder-centered coordinates and then (through different neural pathways) the hand-based coordinates that achieve a grasp on the object seen (76). How the retinal coordinates are translated into shoulder- and hand-based ones remains a matter of contention: Perhaps information is translated into a general spatial model and then out again, or perhaps specialized dedicated translation processes are involved (144). Apparently there are two independent neural pathways involved in the perception of space, called the "what" and "where" systems, the one controlling, for example, our perception of what things are

Another topic neglected here: See References 46, 56, and 156 for maps across time and culture. 
and the other their location in egocentric space $(113,157)$. Findings like this are potentially highly relevant to our topic of the language of space: Landau \& Jackendoff (89) have speculated that the what/where distinction shows up directly as a universal of language, giving us object-names specialized for shape on the one hand, and closed-class spatial morphemes (like our spatial prepositions) on the other. ${ }^{6}$ This general emphasis on egocentric, relativistic concepts of space has been rarely effectively challenged-most effectively by O'Keefe \& Nadel (123; see also 122), who claim that absolute spatial concepts, mental maps of terrain, are encoded in the hippocampus.

Although the notion of mental maps in psychology is half a century old (153), the same bias toward the study of egocentric spatial information and coordination is also to be found in psychology. Thus, for example, in the study of children's spatial abilities, it is suspected that allocentric behavior is actually generated by operations on egocentric information [for a review, see Pick (131)]. In the psychology of language, it has been repeatedly asserted that human spatial language is a direct reflection of our egocentric, anthropomorphic, and relativistic spatial concepts $(24,114)$. Rooted in this tradition is the prediction that all languages use the planes through the human body to give us, as Kant (78) put it (see 159), our first grounds for intuitions about space, in terms of 'up' and 'down', 'left' and 'right', 'back' and 'front'. This prediction turns out to be false, as we shall see, and raises the possibility that this entire tradition partly reflects the linguistic prejudices of the Indo-European tongues.

\section{THE LANGUAGE OF SPACE ${ }^{7}$}

\section{Space as a Natural Domain}

Space is not a restricted semantic domain like (arguably) color or kinship. As a pretheoretical notion it covers at least location and motion, and arguably shape as well-in fact much of what we talk about. What follows uses this unanalyzed notion, itself partly a product of our own cultural preoccupations no doubt, which may conceivably cross-cut emic notions reflected in various languages. Probably few languages have lexicalized the abstract superordinate concept 'space' itself in the way that the European ones have (although for the contrary assumption, see 48). ${ }^{8}$ It is therefore worth asking whether there is

6 Critique can be found in the commentary to Landau \& Jackendoff (89) and in Brown (14, 15).

7

For how to collect information about spatial language, see References 98, 139, 169.

8

For example, there is no obvious locution for 'place' in Tzeltal, although there is a lexicalized concept for 'the place in which an object belongs or is properly kept'. Similarly, although there can be few cultures more preoccupied with places than the traditional Australian ones, the notion of 'place' encoded linguistically is usually restricted to sacred sites (as in Guugu Yimithirr) or to socially "owned" locations [as in Arrernte (55:306, fn 4)]. On the distinction between 'space' and 'place' in Western thought, see Casey (21). 
cross-linguistic evidence for a superordinate domain here. There is at least this evidence: As far as we know (158), all languages have 'where' questions, literal answers to which are spatial descriptions. Not all languages, however, have one superordinate question form: Many distinguish 'whence', 'whereto', and 'where', others 'where (location)' from 'where (motion to/from)', although mostly such forms show morphological relatedness one to another.

There are reasons to think that the spatial domain has internal natural cleavages, according to the intellectual problems posed by the need to describe different kinds of spatial arrays or events. It will be useful to introduce the terminology, following Talmy (149), whereby the thing to be located is the "figure," and the thing with respect to which it is to be located is called the "ground" (alternative fully equivalent terminologies are, respectively, theme vs relatum, trajector vs landmark). (Where the ground or landmark object is the speaker, or another speech event participant, the normal appellation for such descriptions is deictic, but deictic elements of meaning creep into all sorts of spatial descriptions.) Then, restricting ourselves to static spatial arrays, we may distinguish different classes of descriptive problem:

1. No coordinate systems employed:

a. prototype deixis: e.g. F is 'here' near speaker

b. contiguity: "topological” relations: e.g. F is 'on' G

c. named locations

2. Coordinate systems or "frames of reference" employed:

a. Horizontal
i. Intrinsic,
ii. Relative
iii. Absolute

b. Vertical

One may look at these as different strategies that may be employed to locate a referent (or describe its movement). In the first major class, no coordinate system is employed to specify the figure's location with respect to the ground. That is, no angular specification is given: The orange is here fails to specify an angular location from the deictic center, here presumably the speaker, and in the same way The orange is in the bowl does not specify an angle with respect to the bowl in anything like the way The orange is to the left of the bowl does. The strategy for location reference is here 'choose a ground or landmark object in close contiguity with the object to be located'.

A different strategy is to choose a prominent ground object at some remove from the figure or object to be located, and then to specify a search-domain from the ground by specifying an angle from that landmark, as in The orange is to the left of the bowl, Amsterdam is north of Utrecht, or The statue by 
Giambologna is in front of the cathedral. Here the possibilities grow complex, and languages make different resources available.

One may also talk similarly of The bird above the tree, using the vertical angle overdetermined by gravity, our upright stance and normally upright head position. The vertical dimension is special in various ways and is an angular specification that creeps into essentially nonangular topological specifications, as illustrated by The orange on the table (about which more later).

I now describe something of what we know of cultural and linguistic variation on these different parameters. Note that this way of carving up the pie (though indebted to many predecessors and colleagues) is my own (for more justification, see 102), and the reader interested in other treatments should see References $6,65,114,147,149,160$. One advantage of the present scheme is that it handles extensive and intensive field data from a score of non-IndoEuropean languages under investigation at the Max Planck Institute for Psycholinguistics - data that other schemes are likely to founder on. Incidentally I treat motion and static location in parallel. Talmy (149) has influentially argued that motion is primary, static description derived, sometimes as "fictive motion"-I believe this itself to be a cross-linguistic variable (103).

\section{Deixis}

Deixis is the way parameters of the speech event enter into the interpretation of linguistic expressions (for elementary exposition, see 97, 101; for complexities, see 75, 110; and for good cross-linguistic surveys, see 1, 165; see also 32). Such parameters can enter into spatial expressions in different ways:

1. Central: In deictic demonstrative pronouns like this or adverbs like here, what is denoted depends largely on the contextual parameters (crudely, one might gloss here as 'the contextually appropriate area including the speaker'). Similarly for motion, come denotes motion toward the deictic center, usually the speaker.

2. Compositional: when one adds a deictic to an already well-formed spatial description ( $\mathrm{cf}$ The cup is at the side of the table with The cup is at this side of the table).

3. As optional origo: where a speech participant is used as a center or origin for a coordinate system (often incidentally), as in The ball is to the left of the tree (from where I am standing), or It's thirty miles north (from where we are now).

This discussion is restricted to the central cases, like deictic adverbs and demonstratives, and motion verbs like come and go. There is well-known cross-linguistic variation in the size and structure of inventories of deictic demonstratives, which have been ably reviewed elsewhere (see especially 1 and references therein), and I note only the kinds of variation involved. First, one 
needs to distinguish between speaker-centric systems (where a distal demonstrative glosses as, for example, 'that, away from speaker') and systems organized around other participants as well (where, for example, a distal demonstrative might gloss as 'that, near you', which may even be opposed to another 'that, near him'). This opposition should be of fundamental sociological importance, but little has been done on the actual usage of systems of the latter kind (but see 26). Second, additional spatial parameters are often built into demonstrative series. For example, some Papuan languages, in addition to marking horizontal distance from speaker and addressee, also indicate vertical location relative to the speaker (thus providing terms glossing e.g. 'that far away up there' vs 'that far away on the level' vs 'that far away below'). Other Papuan languages build in geographic features, with forms glossing 'that north' or 'that there inland' (see 43:75-77). The Eskimo languages are justly renowned for their enormous demonstrative series, sometimes incorporating shape distinctions, geographical distinctions (e.g. along coast, away from coast, upriver, downriver), visibility conditions, and the like $(44,73)$.

Sociological reasons for variation in demonstrative inventories have been the focus of various speculations, e.g. by Kay (80), Denny $(32,33)$, and most recently by Perkins (129). A leading idea is that in small-scale speech communities without literacy, language use is fundamentally more contextually dependent than in complex speech communities. Using a sample of 49 languages, Perkins claims that deictic distinctions are indeed more numerous and more grammaticalized in small-scale speech communities (but see 25 for critique). In fact such global speculations are unlikely to be reflected directly in the size of demonstrative series. For one, indexical language is at the heart of all language socialization (121); for another, context-dependence is a feature that is found in many other areas of vocabulary. A more promising general line of investigation, which attempts to relate sociocultural factors to systems of demonstratives and their grammatical properties, is exemplified by Hanks's work (53, 54; see also 26$)$.

Seen as one kind of strategy for locating objects in space, deictic demonstratives (at least those that do not incorporate geographical or orientational features) may pragmatically succeed in indicating distance but fail to indicate angular location on the horizontal. It is for that reason, presumably, that they are often accompanied by gesture. The study of gesture has in recent years blossomed, but there still remains relatively little good observation of pointing gestures and their interpretation. A notable exception is the work of Haviland $(59,60)$. Haviland's work makes clear that here again is an area ripe for ethnographic investigation: Far from being the self-evident "roots of reference" (in Lyons's phrase), the very opacity of a pointing gesture in another culture indicates just how complex and socioculturally dependent are the grounds for deictic interpretation. 
Deictic verbs of motion have received less attention. In some languages, e.g. the Mayan ones, they belong to an elaborate series of motion verbs, many of which incorporate deictic parameters (e.g. 'arriving here' vs 'arriving there') (see e.g. 58 on Tzotzil; 13). On grounds of systematicity and parsimony one might suspect that verbs of motion should reflect the kinds of distinction made in demonstrative series. This is sometimes the case, so that Palauan, for example, which has demonstratives glossing as 'this near speaker', 'that near addressee', and 'that near neither speaker nor addressee' has corresponding motion verbs 'come toward speaker', 'go toward hearer', 'go away from both speaker and addressee' (1:279). However, recent work suggests that 'go' verbs rarely actually encode 'motion away from deictic center'-rather, they are unmarked for deictic distinctions, and only by opposition to the deictically specified 'come' verbs pick up a Gricean conversational implicature of 'motion away' (168). It could be that distal deictics like 'that' and 'there' are similarly unmarked, and it is for this reason that their usage is notoriously difficult to pin down.

\section{"Topological" Notions}

In a work that has had tremendous, though often indirect and unrecognized, impact on the study of spatial concepts, Piaget \& Inhelder (130) argued that the child passes through a series of stages of spatial reasoning: At first it grasps only topological notions, then much later grasps Euclidean notions of metric distance and angle, and finally grasps projective geometrical notions. ${ }^{9}$ Topology, sometimes described as "rubber-sheet geometry," is the study of geometrical properties that remain constant under transformation or "deformation." Thus a sphere and a cube are topologically equivalent, and together they are distinct from a doughnut or a bicycle tire. Piaget discovered that children less than four will, under the right circumstances, conflate circles, ellipses, and squares, while distinguishing objects with holes in them. Children's drawings, in their disregard for the order and location of eyes, nose, and mouth also seem to follow topological principles. ${ }^{10}$ Spatial relations between two objects of undistinguished shape and size are limited to primitive kinds: Piaget listed proximity, order, enclosure, and continuity. Thus semantic notions like NEAR, AT, BETWEEN, IN, etc have been called topological. Children do learn linguistic terms for these notions earlier than other kinds of spatial vocabulary, at least in those European languages whose acquisition has

9 For anthropological work that attempts to build directly on these Piagetian stages, see Hallpike (52) on "primitive thought" and Wynn (175) on hominid spatial competence as expressed in tools.

${ }^{10}$ Piaget's work has been heavily criticized in the light of recent studies of infant cognition. Babies apparently know things Piaget has been thought to think they don't. However, the criticism often neglects the careful distinction he made between perceptual and cognitive or "representational" faculties, the former being by his own account fully in place by twelve months. 
been intensively studied $(77,142)$. This may differ for other languages (see below).

Much analytic and descriptive work has been done on this kind of spatial language, which is often encoded in closed-class morphemes, e.g. prepositions or local cases. A review of this work lies beyond the present scope, but see Miller \& Johnson-Laird (114) for semantic treatment; Herskovits (65:127-56) for a careful consideration of the range of uses of English at, in, on; Vandeloise (160) for corresponding French expressions; Talmy (149) for ideas about the relation between topological notions and closed-class grammatical morphemes; and Landau \& Jackendoff (89) for alleged neurophysiological bases.

Some more recent developments should be reported. One is the now considerable work on the diachronic "evolution" of (largely topological) spatial morphemes (especially pre- and post-positions) from other sources, for which see Heine et al (64) and Svorou (147) and references therein. This literature makes clear that body parts are a frequent source for such closed-class items, and it has been claimed that this mapping of body to world is an essentially metaphorical process $(19,88)$, an analysis critiqued for at least one language in Levinson (100).

Much of the cross-linguistic comparison of spatial expressions has been done on the basis of existing grammatical descriptions. This is a perilous enterprise, since there is rarely any proper description of the meanings of these expressions in grammars, and instead an assumption that the English gloss 'in', 'at', 'on', etc, map one-to-one to the foreign language. More careful comparisons reveal substantial differences even across closely related languages like English and Dutch. Looking just at IN and ON notions, Bowerman \& Pederson $(9,12)$ have shown that one way to look at the variation is to make a list of different situations that may be covered by an 'in' or 'on' expression (expressions that include prototypical containment and vertical support situations), and then see whether any cross-linguistic patterns emerge. They find that the situations covered form an implicational hierarchy, so that, for example, any language that extends the prototypical horizontal 'on' relation such that it considers a ring to be 'on' a finger will certainly consider a spider to be 'on' the ceiling.

However, such orderly variation is only part of the picture. Some languages simply fail to exhibit any direct coding of IN, ON, or AT notions. This is sometimes because they fractionate these meanings as it were, so that, for example, in the Mayan language Tzeltal, IN-notions are distributed across a range of locative predicates specialized to differently shaped containers (15). Or sometimes they fail to encode them altogether. Thus in the Australian language Guugu Yimithirr the vertical dimension is a major axis that has no topological, contact-only expression: ABOVE and ON are not distinguished 
and IN is expressed by metaphor, while AT notions are expressed primarily by the locative case, which also has rather broader meanings.

The corresponding motion events, such as 'put in' or 'enter', also show fundamental cross-linguistic variations. Talmy (150) noted a tendency for languages to adopt one of two major lexicalization strategies: to package the spatial path with the verb (as in enter, exit, insert) or instead to package the path separately as a satellite, i.e. particle or adverb (as in go in, go out, put in, etc). English favors the latter lexicalization pattern, while borrowing some exemplars of the other pattern from the Romance languages. Slobin (143) has explored how children acquire these patterns and how they come to constitute a way of "thinking for speaking," therefore patterning the construction of discourse as well. This typology, however, which turns out to be somewhat leaky, should not distract from the very different ways that languages construe path distinctions in the first place. In an important comparative study of language acquisition, Choi \& Bowerman (23; see also 9) showed that Korean classifies 'putting in' or 'putting on' situations in quite different ways than English: In Korean the relevant distinction is not 'in' vs 'on' but 'tight fit' vs 'loose fit'. A close look at the linguistic development of children raised in Dutch-, English-, Tzotzil-, and Korean-speaking homes shows that children do not start from a common conceptual core, given say by innate presumption or biological endowment, but from the earliest point of language production already make distinctions more like adult speakers of their own languages (10). Recent work by the same authors shows that children are already sensitive to the language-specific distinctions in comprehension before they are able to produce the relevant expressions at all (11). As Bowerman (9:170) concluded with respect to the production evidence, "there was little evidence that [the children] had strong prelinguistic biases for classifying space differently from the way introduced by their language. This leaves the door open to the possibility that, after all, spatial thought — undeniably one of our most basic cognitive capacities-bears the imprint of language."

\section{Named Locations}

A final solution to spatial description that avoids substantial Euclidean geometry is to proliferate named locations. One can then state that the figure is 'at' the named location. Of course there are many ad hoc locutions that can be employed here, but speech communities do also standardize place names to a greater or lesser extent. The study of toponyms has, of course, been long of interest to historians, and the patterns in the Old World are extensively documented, but the scientific study of place-names from a sociolinguistic or anthropological point of view is in its infancy. Hunn (71) has made provocative suggestions for such a study, noting that the density of place names in huntergatherer societies follows certain laws, and that the nomenclature, like ethno- 
botanical nomenclature, systematically varies from monolexemes to descriptive phrases according to taxonomic hierarchy and cultural importance (see also 79). My own field experience in village Tamilnadu, where fields had individual names that also came to designate their owners in colloquial parlance, suggests a rich sociology here. With growing interest in indigenous land rights, it is likely that this is an area of study that will prove of increasing interest.

\section{SPECIFYING LOCATION WITH COORDINATE SYSTEMS OR FRAMES OF REFERENCE}

It has long been noted that The cat is behind the truck is ambiguous based on a reading where the cat is at the truck's rear and a reading where the truck is between the speaker and the cat, regardless of the orientation of the truck. This ambiguity draws attention to the existence of different frames of reference, as they were called in Gestalt psychology half a century ago, in effect different coordinate systems. In the first intrinsic reading, we employ a coordinate system based on the truck, use the truck's asymmetries and functions to find a named side, and project out a search domain from that named side, within which the cat is to be found. In the second deictic or (as I prefer) relative reading, we employ coordinates based on the speaker (or some other viewer), find a truck, and project out a search domain on the occluded side of the truck such that the cat may be found within it. (This is actually an oversimplified description; see below.)

Although fairly complex geometrical notions, involved with coordinate systems, search domains, and the like are involved in each case, evidence shows that the intrinsic system is in some sense simpler. Children learn the intrinsic uses of 'front' and 'back' notions earlier than the deictic or relative ones (77). Indeed there seems to be an implicational universal that if a language has deictic/relative notions of this kind, it will have intrinsic ones, but not necessarily vice-versa. Finally, there are logical asymmetries: The intrinsic notions are binary relations, the relative ones are covertly ternary; the intrinsic notions fail to support spatial inferences, the relative ones do so (94, 102).

The standard references either fail to note or downplay the existence of a third frame of reference, which I shall call the absolute, most obviously exemplified by cardinal directions like north, south, east, and west. Languages and cultures in which this kind of coordinate system forms the central means for specifying locations, regardless of scale or context, have been documented only recently.

Before proceeding to these three systems, it should be noted that there is some unclarity in the literature over whether frames of reference are a linguis- 
tic matter at all. Because we can use the same words, say The cat is behind the truck, for two different construals, perhaps behind is semantically nonspecific with regard to reference frames, just as big in That book is big is nonspecific with regard to which dimensions are large. Psychologists have found this tempting (see e.g. 20), and linguists have encouraged them by assuming the same expressions can always be used across reference frames (see e.g. 147: 23). In fact, although there is a tendency for some ambiguity across reference frames, there are often entirely distinct terms associated with each. A second general issue is whether the typology of reference frames across languages is more a matter of contexts of preferred usage (so that, for example, we prefer relative expressions like in front of for visually perceived arrays, but north of for geographical scale references) than of grammatical stipulation. Although there is some room for dispute here, the evidence suggests that there are languages that scarcely use at all one or more of these frames of reference; that is, the linguistic resources are simply absent in some cases. (In other cases, the linguistic resources may be present, but the cognitive abilities necessary for their correct use largely absent: It is not unusual to find cultures that supply linguistic terms for left and right, but where the speakers are confused about how to use them, or cultures like the European ones whose languages have good cardinal direction terms like north, but scarcely anyone knows where north is.)

We may now proceed to details.

\section{The Intrinsic Frame of Reference}

In the intrinsic frame of reference the figure object is located with respect to what are often called intrinsic or inherent features of the ground object. The locutions are bad because there is often nothing intrinsic, and everything is culturally imposed and assigned in the isolation and designation of these features. Consider for example the phrases in front of the TV, in front of the steps, in front of the church, in front of the ship, in the front of the book, etc (in the relevant nonrelative or "nondeictic" sense ${ }^{11}$ ). Clearly the notion 'front' of an object is not an inherent property: In the case of the TV it is based on canonical viewing position, in the case of the steps on the direction they are ascended and not descended, in the case of the Church the west end regardless of the ordinary entrance, in the case of the book the first few pages, in the case of the ship the direction of canonical movement, etc. Various underlying principles may be discerned, and their relative priorities observed. Thus, direction of

\footnotetext{
${ }^{11}$ Note that the intrinsic reading is often forced by the definite article, which in turn constrains the preposition: thus at the front of the TV, but in the front of the book. There has been relatively little work on the way these collocations select interpretations, perhaps because things look messy-for example, the definite article in to the left of Bill fails to resolve the ambiguity.
} 
motion is secondary to direction of sense organs as shown by the designated fronts of crabs $(41 ; 114: 402-5)$. Although the designation of English front is such a complex amalgam of orientational, perceptual, functional, and other cultural factors, the correct use of the word is not merely a matter of rote learning: Two-year-olds can assign fronts to objects by a generally correct algorithm of some kind (96).

The English intrinsic system can be thought of as a six-sided box-like armature that is imposed on objects. The cubic armature is oriented by gravity, so the top side of an object is uppermost, and the bottom the underneath facet. Front and back are found in the way sketched in the previous paragraph, by taking "perceptual apparatus" (as with animals, cameras, etc), canonical direction of motion, canonical direction of use, etc into account. The two remaining facets are the sides. If the object is animate, it may have its own left and right side, if not, it may inherit its left and right from the human beings who wear it or drive it or sit in it. If human beings characteristically confront it, as they do with desks, cupboards, and mirrors, the left side is transferred from the closest human left side (114). Objects can obviously resist these assignments, if like cubes and balls they lack both inherent and functional asymmetries.

Although a fair bit of work has been done on corresponding notions crosslinguistically (see e.g. 147 and references therein), it mostly fails to examine the actual semantics of the systems, making them appear cross-linguistically more similar than they actually are. For example, Tzeltal has body-part terms that at first sight look a bit like English 'front', 'back', 'sides', and so on. Yet the system works in a totally different way (see 28 for a similar Tzotzil system, 111 for a contrasting Zapotec system, 106 for a quite different Totonac one). There is no fixed armature at all, and certainly no fixed orientation (of the kind that gives us English top). Instead, the system is driven by an axial geometry together with an analysis of shapes, which scarcely refers at all to human use or orientation. Thus the 'face', 'back', 'stomach', 'nose' of a stone or novel object are assigned regardless of its orientation, its use, or any viewing angle. This is consistent with other aspects of Tzeltal spatial description, in which, despite appearances, the human frame plays almost no part in the actual concepts employed (100). Another kind of cross-linguistic variation occurs in the perception of asymmetries: English may assign a top and a bottom to a cube or a sphere, but the Tzeltal body part terms resist this. English considers a tree to lack intrinsic fronts and backs, but Chamus considers otherwise (63). The way in which objects are partitioned into named facets is related in some way, not yet fully clear, to the ways in which they are assigned dimensions [of the 'length', 'width', 'height' type (7)], on which subject there is just beginning some cross-linguistic comparison (see 90, 145 and references therein). 
These details may seem of little interest to the nonlinguist but in fact they can have important cultural corrolates. For example, consider the labeling of the interior sides of a building. For us, the front of a church or cinema is the side to which the audience is oriented, and audience left determines building left. This is so for the Pohnpeians as well. Like many peoples, they value the right side. When the high chief sits in the assembly hall facing the commoners, should lesser chiefs sit on his left, or on his right to the building's left? In choosing the latter solution, which allows, for example, a uniform left-side-ofbuilding alignment for women, Pohnpeians opt for the intrinsic orientation of the containing building, thus perhaps symbolizing the coherence of the entire social system $(82,83)$.

The intrinsic frame of reference can also be used to describe motion. Thus The truck is moving backwards, or It's turning right (not in the sense of 'right from my viewpoint') uses the truck's assigned intrinsic facets to indicate directional characteristics of motion. Perhaps one might gloss It's turning right in terms of the truck being at location L1 at $\mathrm{t} 1$ and at L2 at $\mathrm{t} 2$, such that L2 is at the right side of the truck at $\mathrm{t} 1$. It is interesting to note that motion allows objects that would otherwise resist the assignment of intrinsic facets to now acquire them. Thus, if a cube is sliding down an inclined plane, its leading edge can be called its front, and it could now be said to veer to its left. Perhaps we should think about the path itself as having intrinsic properties assigned to it, which then determine the named facets of the moving object. If the truck is reversing and is said to be turning right, my intuition is that the truck's intrinsic left and right are now reversed. If so, this suggests that facets assigned on the basis of motion can overrule those based on other intrinsic criteria. When we give route directions, we typically use these intrinsic sorts of locutions: go forward, turn to the left, then take the next right, and so on. We can describe abstract diagrams and patterns in the same terms, using fictive motion or an imaginary tour (95).

The intrinsic frame of reference is close to linguistic bedrock. Although there are languages, such as the Australian language Guugu Yimithirr (57, 99), that use it minimally, most have fairly elaborate systems of one kind or another. There are also languages that almost exclusively rely on it [e.g. Mopan (27)]. Children appear to acquire it earlier than other systems (77). All this is puzzling because the principles for assignment of intrinsic facets are culture-specific and often highly complex, as illustrated above. The puzzlement increases when one considers the logical properties of intrinsic expressions, which are incapable of supporting any sustained spatial inference (94). The explanation for the prominence of the intrinsic frame of reference is probably that the relations are conceptually simple in one respect: They are binary, unlike the covertly ternary relations in the relative frame of reference. 


\section{The Relative (So-Called Deictic) Frame of Reference}

One reading of The cat is behind the truck is similar to The cat is behind the tree; namely it has the truck or tree between speaker or viewer on the one hand, and the cat on the other. This is clearly a ternary relationship between points: viewer, truck, cat. Many languages, English among them of course, have 'front', 'back', 'left', and 'right' expressions with this kind of ternary relation, but they are also often ambiguous between this and a binary intrinsic relation of the kind just reviewed. Piaget correctly predicted that the ternary relation should be hard for children to learn, and in fact the 'left'/'right' uses may not be fully acquired until age 11 or 12 . Nevertheless, it is this system that many authors from Kant (78) onward have considered fundamental to human spatial cognition.

The complexity of these systems is such that the correct analysis of such ternary 'left', 'right', 'front', 'back' systems is still, despite considerable work, quite unclear. The problem is that whereas an intrinsic left, right, front, back system, in its descriptions of the regions around myself, has my right clockwise from my front, a relative ternary system like the English one (there are others mentioned below) has the right of the tree anticlockwise from its front! Here is one explanation $(24 ; 65: 156-92)$ : We assimilate the tree to the "canonical encounter" where speakers face each other, hence the front of the tree is toward us; but we fail to make the rotation of 'left' and 'right' because that is too conceptually complex. The problem with this account, however, is that, apart from cultural variability in preferred positions for verbal interaction, children in fact learn to make the rotation to others' lefts and rights by age five or six, long before they master this mixed-up system! Another explanation is that the terms front and back in this usage have nothing to do with 'front' and 'back': in front of in The cat is in front of the tree simply means 'between me and', while behind in The cat is behind the tree means 'is occluded from my viewpoint by' or something similar (114:399-400). Such a bruteforce solution hardly satisfies our feelings about what kinds of notions are lexicalized in natural languages, but a more serious objection is that on this account there is no explanation for the frequent ambiguity in many languages of 'front'/'back' terms between an intrinsic and relative interpretation, for there would be simply nothing in common between the relevant semantical notions.

I believe that the correct solution is that these relative ternary relations often introduce a secondary coordinate system. In English, the primary coordinate system is based on the viewer, so that The cat is to the left of the tree could be glossed as something like 'from this viewpoint, the cat is further left in the visual field than the tree'. But for the front/back terms we map a secondary coordinate system onto the tree under 180 degree rotation (following the 
canonical encounter idea if you like), so that the tree is now assigned a 'front' and a 'back'. Now The cat is in front of the tree means just what it says: The cat will be found in a region projected from the front of the tree, where 'front' is found by a 180 degree rotation of the viewer's front about the tree.

It may be objected that this results in a fundamental difference between the 'left'/'right' terms (which don't involve a secondary coordinate system) and the 'front'/'back' terms (which do). But for many languages, this is probably correct. Thus Hausa prefers an interpretation under which 'in front of' means what English 'behind' means. The secondary coordinates are translated but not rotated. However, Hausa also allows a less-favored English-like interpretation of the 'front'/'back' terms. In either case, the 'left'/'right' terms stay constant (67). The same appears to be true of actual Japanese usage in spatial tasks (K Inoue, personal communication). This potential independent flexibility of the 'front'/'back' terms would depend on the variable mapping of the secondary coordinates. In some languages, the 'left'/'right' terms may also rotate with the variable assignment of 'front'/'back' terms. Thus, in Tamil both an English and Hausa-like assignment of 'front' and 'back' are possible, but 'left' and 'right' may then flip too. In this case, 'left' and 'right' are also determined by a secondary coordinate system.

The use of primary and secondary coordinate systems makes the details of these relative systems complex. Why have peoples and languages bothered to develop such systems? One answer is that intrinsic systems alone appear fairly inadequate. First, not all useful landmark objects (like rocks or trees) will necessarily offer distinguishable facets by the local intrinsic criteria. Second, relative systems do support proper logical inferences: If A is to left of B, and B to the left of C, then A is to the left of C (94). A third potential advantage of these systems is that they hook up to visual experience in a very direct way. A visual memory of a scene provides all the information that I need to describe it in relative terms. Actually, the degree to which such systems are visually defined may itself be an interesting cross-linguistic variable (e.g. Does 'behind' require partial occlusion?).

Relative systems of spatial description build in a viewpoint and are thus essentially "subjective." For this reason they have been called deictic, although it is important to see that such descriptions are not necessarily egocentric: The viewpoint need not be the speaker (It's to the left of the tree from where you are sitting), nor any participant in the speech event (as in The goalkeeper deflected the ball to the left of the goal). The nondeictic uses may be thought of in terms of a relativization to text $(1,42)$ or in terms of Bühler's "transpositions" $(53,60)$. Alternatively, one could think about the deictic uses as just special (if normal) uses of a viewpoint-dependent system, which is itself not essentially deictic. 
Such systems allow the description not only of static arrays but also of motion events (as in The squirrel ran behind the tree). In such descriptions the viewpoint is normally held constant. One reason is that their logical structure has the same contextual dependency as deictic inferences generally. Just as $I$ am taller than you, you are taller than Bill, so I am taller than Bill fails as an inference if the speaker and addressee change midway, so logical inferences of the kind if $A$ is to left of $B$, and $B$ to the left of $C$, then $A$ is to the left of $C$ fail if the viewpoint changes. By holding the viewpoint constant, we can describe not only motions, but also describe patterns as fictive motions, as in The line runs up, then left, then up, then right (95). This holding static of the viewpoint limits the utility for the description, for example, of long and complex journeys, and as suggested above route directions are usually given using intrinsic 'left', 'right', 'front', 'back' notions. ${ }^{12}$

\section{The Absolute Frame of Reference}

Many speech communities make extensive use of fixed bearings, or absolute coordinates, like north, south, east, and west. Conceptually, cardinal directions are very abstract notions. A notion like 'north' cannot be thought of as a proximate place or landmark, because then if we moved sideways the bearing would change. Rather, it defines an infinite sequence of parallel lines-a conceptual "slope"-across the environment. Nor does it matter what defines the slope, just so long as everybody in the speech community agrees: These are cultural conventions, not "natural" directions, whatever basis there may be in the environment. The sun's rising and setting cannot directly determine fixed bearings of any accuracy due to solstitial variation, and cultures seem to settle on fixed bearings that are abstracted from varied additional sources, from seasonal winds, to mountain inclines, to coastal alignments, to river drainage directions, to star-setting points. Given these varied sources, there is no need for such systems to give us quadrants or orthogonal axes, although many cardinal direction systems have those properties.

Absolute direction systems give us external bearings on an array, but without employing viewpoints. They are "allocentric" systems. Local landmarks can give us some of the same properties, especially within a restricted territory, but they do not have the same abstract properties as notions like 'north'. The point is made vivid by many Austronesian island languages, which fix an

\footnotetext{
${ }^{12}$ How would one know? Suppose that the route to be described had a shape approximating a capital $\mathrm{P}$ without the final join between the loop and the upright. A relative description might go Go straight ahead, turn right, then come back this way, then left, while a more natural intrinsic route description would go Go straight, turn right, then straight, then right again (95). It will be harder to distinguish the two systems when the relative system is successively transposed or deictically shifted to each step of the journey, but then we would expect the ternary relations presupposed by locutions such as Take the alley to the left of the gas-station.
} 
East-West absolute axis by reference to the monsoons but use a 'mountain''sea' axis to contrast with it. As one moves around such islands the one axis remains constant, the other rotates (124). Truly intermediate cases may be the riverine systems of Alaska, which operate as abstract systems within a vast drainage area but are reset when crossing into another drainage system (93). Many systems that take their terminology from local landmark features are in fact fully abstracted. For example, Tenejapan Tzeltal abstracts a north/south axis from the mountain incline of the local environment, but the axis remains constant outside the territory (17). In fact, the very wide distribution of systems of these sorts may have been missed because the terminology, in terms of hillsides, river directions, coastal features, and so on, may have appeared directly referential. ${ }^{13}$

Absolute systems yield elegant spatial descriptions of all sorts and scales of spatial arrangements. Just like relative 'left', absolute 'north' is an implicitly comparative relation (cf 'bigger than') that allows complex spatial inferences. Thus if A is north of B, and B is north of C, A is north of C. But an absolute system has the logical superiority that the validity of such inferences is not relative to a fixed viewpoint, as it is with 'left' or 'right' (or 'in front'/'behind'). In fact it is by far the most elegant solution to the problem of angular descriptions on the horizontal. There are just two catches: (a) Such systems do not catch egocentric constancies-e.g it is impossible to give a general recipe for setting the table in such terms, with forks on the left and knives on the right; $(b)$ to use such systems speakers and addressees must be constantly and correctly oriented to the local fixed bearings (more below). These difficulties might lead one to expect that such systems would be learned late by children, but apparently they are learned earlier than relative expressions $(29,30)$.

Motion descriptions are as natural in these systems as are location specifications. Some languages even use cardinal directions as verb roots [e.g. Kayardild (39)]. One special feature of absolute motion descriptions is that they allow the specification of direction without any reference to places: One can talk happily of birds heading north, ships sailing east, winds blowing west, and so on, without reference to sources and goals, which are often thought to be essential to the description of motion events. Similarly, one can specify alignments, e.g. of mountains or rivers, without reference to locations.

Such systems are of special interest when they occur without a corresponding relative system of 'left', 'right', 'front', 'back' terms. Then descriptions of most spatial arrays, even in small-scale space, must use absolute terminology. Such descriptions classify spatial arrays in a very different way than our own relative sort of system. For us, a cup to the left of a bottle becomes a cup to the

${ }^{13}$ For this reason, among others, I doubt the generalization that cardinal direction terms are frequently derived from body-part terms (see 14). 
right of a bottle when we walk around to the other side of the table, but in an absolute system the cup remains, say, north of the bottle from any viewpoint. On the other hand, constancies that we have built into our cultural environment, such as gear-stick to right of steering wheel, are constantly varying assemblages under absolute descriptions. Cultures favoring absolute frames of reference may build cultural environments that have constancies that may be "invisible" to our kind of cultural description [e.g. windbreaks to the east (118)].

\section{THE VERTICAL DIMENSION}

Our three frames of reference can equally be distinguished on the vertical axis. Suppose a fly hovers above an upright bottle. The three frames of reference coincide - the fly is in line with the top of the bottle (intrinsic), it appears above the bottle in my visual field (relative), and it is higher in the axis defined by gravity (absolute). However, if the bottle is on its side and the fly is vertically above, the intrinsic frame has the fly by the side, not above the bottle. In English, the intrinsic frame of reference is now eclipsed, although if you lie down with the fly in the same axis as your trunk, "The fly is above your head" may be acceptable (20). If I, the speaker, lie on my side, it gets better still. Because intrinsic tops, relative viewpoints, and gravitational fields normally align, we scarcely notice the possibilities that the frames of reference may fail to coincide. Therefore, the vertical dimension is usually massively overdetermined and unproblematic (and always ripe for symbolic exploitation). Perhaps because of that, elements of vertical meaning intrude into intrinsic descriptions, so that in English the top of the bottle is that part that is canonically vertical. Absolute systems often build the vertical dimension into the relevant linguistic system, so that in Australian languages, for example, 'up' and 'down' are often the same specialized part of speech as 'north', 'south', 'east', and 'west'. In fact, some Mayan languages may have systematically collapsed 'up' and, for example, 'south' for symbolic purposes (17, 146).

\section{LANGUAGE AND COGNITION: WHORFIAN EFFECTS?}

Linguistic details are, so it may appear, matters for linguists. However, when those details correlate with larger things, they come to have a much broader interest. The language of space correlates with many other realms of experience; for example, with details of the symbolism of values, with kinesics, and with material culture and aesthetics. The connecting linkage, the intermediate variable, is of course cognition. There are at least some grounds for thinking that language plays a causal role in the relevant cognitive specializations. 
Every linguistic distinction must be supported by the relevant conceptual distinctions, perceptual acuities and mental algorithms. For example, take the intrinsic frame of reference: one can usually apply 'front', 'back', 'side' appellations to asymmetric objects, however novel (although in English one may need to know something about functional properties of the object). There must be an algorithm to achieve this (see e.g. the sketch in 114:403). To apply the Tzeltal body part system to novel objects, one needs to carry out a specialized geometrical analysis, but no ancillary functional information is needed (100). The application of the relative frame of reference requires instant access to knowledge of left and right, a notoriously fallible procedure, despite endless practice and systematic skewings in our constructed environments. Where the conventions allow mappings of secondary coordinates under both rotation and translation, as in Hausa and Tamil, there have to be procedures for determining which mapping is pertinent.

Most obviously of all, to use an absolute frame of reference on a range of scales, e.g. the table top in front of you, one needs to have instant access to the relevant fixed bearings. If you ask a European to point to north, she is likely to be flummoxed, which shows that her system of cardinal directions is more about the orientation of paper than of places. Speakers of languages that use the absolute frame of reference where we would use a relative one can be shown to be always oriented. Indeed, knowing where 'north' is will not be sufficient. One also needs to know the correct bearings from one's current location of all other locations to which one may want to refer; in short, one needs to "dead reckon," keeping track not only of directions but also of metric distances. Some direct evidence for this ability is available for speakers of relevant Australian languages $(99,107,108)$, a Mayan language [Tzeltal (SC Levinson, unpublished data)], and a Khoisan language (166:209-27), but apart from a handful of such observations, and despite the interest in huntergather exploitation systems, there is an amazing gap in systematic study here. Knowing that such computations are unconsciously and routinely carried out (as explored by surprise tests) does not tell us how it is done. In the Guugu Yimithirr case the native exegesis points to many environmental clues, but how these are integrated in constant background computation is unknown (99).

To explore the cognitive background to the use of frames of reference in language, one can devise a simple set of field experiments (3). These exploit various logical and rotational properties of the three main frames of reference mentioned above. For example, imagine a mouse facing a block of cheese, both on a bread board. In the intrinsic frame of reference, if this is coded as 'cheese in front of mouse', the description will remain true when the observer wanders around the board, or even when the board is rotated. The absolute description 'mouse north of cheese' will remain true as the observer wanders 
around, but not if the board is rotated. The relative description 'mouse to left of cheese' will become false when the viewer walks around to the other side, or when he stays constant and the board rotates. Thus conceptual codings in each of the different frames of reference have different tolerances to (or different truth conditions under) rotations of these kinds (102).

These properties can then be exploited to explore aspects of memory, inference, and other cognitive operations. For example, persons facing a table can be asked to memorize an arrow facing to their left, and as it happens, south. They can then be rotated 180 degrees and asked to recognize which arrow they saw before from two on another table, one facing to their left and north, the other facing to their right and south. If they choose the arrow that preserves the left-facing property, we can be fairly sure they are using a relative frame of reference to memorize spatial arrays. If they choose the arrow that preserves the south-facing property (hence the rightwards-pointing one), we can be fairly sure they are using an absolute frame of reference. We can elaborate this methodology to explore different kinds of psychological capacity (18, $127,140)$.

There are two ways to explore the relation between language and cognition in this way. One is to predict that if a language or speech community employs specific frames of reference to describe arrays of certain sorts, then members of that speech community will use the same frames of reference in nonlinguistic tasks, i.e. in memory or inference and in spatial thinking generally. (Note that the predictions are only clear where the language in question excludes certain frames of reference.) Languages and their speakers can then be typed, the predictions made and tested over a wide range of languages. The results obtained suggest that this is indeed a reliable prediction: We think spatially in the frames of reference that our languages make prominent $(3,126,127,161)$. Another way to explore the linkage between language and cognition is to explore the linguistic systems and cognitive repercussions in depth in particular field sites. This has been done for example in Tenejapan Tzeltal (18, 102, 104), where it is possible to show that the linguistic use of an absolute frame of reference is correlated with the use of the same frame of reference in recall, recognition, inference, and even gesture.

These findings show that specializations in spatial language correlate with nonlinguistic coding strategies or cognitive styles. Although proper caution is in order before presuming causality from correlation, it seems inescapable that language plays a crucial role in forming and standardizing such cognitive styles within a speech community. ${ }^{14}$

\footnotetext{
14 Incidentally, the fact that peoples of similar material culture and ecology, even related cultural history, can vary fundamentally in their preferences for frames of reference will rule out any simple ecological determinism here.
} 


\section{LANGUAGE, COGNITION, AND CULTURE}

It was suggested above that cognition is the intermediate variable between language and other aspects of culture. Thus we would expect specializations in cognitive style correlated with spatial language to surface in other cultural manifestations. As yet, the work that would show this has scarcely been begun. But consider the following examples.

Tenejapan Tzeltal uses no relative frame of reference, and thus no 'left', 'right', 'front', 'back' terms for spatial reference in that frame. Although Tenejapans have terms for left and right hands, they do not extend these freely even to other parts of the body, let alone to spatial regions (105). Nor do they, contrary to the predictions of Hertz (66) and Needham (119), subscribe to the allegedly universal symbolism of 'left' and 'right'. Their material culture, from domestic architecture to weaving, favors symmetry, and they have difficulty distinguishing figures reflected about a vertical axis. Instead, in line with their emphasis on the absolute frame of reference based on their sloping territory, they subscribe to a cosmology of the inclined plane, with the ceremonial center south and upward, and the corral of the souls in the lowlands. Time is conceived of as stretching up to the south. This localization of time and space, mythic and real, allows gestural depiction. This picture contrasts with some other Mayan cultures, e.g. the Mopan, where an intrinsic frame of reference is predominant, a frame of reference that defeats extended spatial inferences, like transitivity. The associated complex of features seems to run way beyond spatial thinking altogether, into details of the kinship system for example (27). ${ }^{15}$

It is a commonplace of the Australianist ethnography that landscape and locality are the media on which cultural knowledge and social history are written. Spatial orientation is the key to understanding myth, art, camping arrangements, gesture - almost every aspect of social life $(117,134,137,148)$. The languages (mainly) emphasize the absolute frame of reference (59-61, $91,167,170)$. Cognition follows suit $(86,99,104,107,108)$. Gesture and language $(59)$ and handsign and sand-drawing $(84,116,171)$ are deeply intertwined. Although the complete picture has yet to be painted, there is little doubt that the key to understanding much of this intricate cultural detail, and

\footnotetext{
${ }^{15}$ For a collection on spatial description in the Mayan languages see Haviland \& Levinson (62), and for Mesoamerican languages more generally, see de León \& Levinson (31). Incidentally, such regional comparisons can be most revealing; there is plenty of material but no synthesis for the Australian cultures and languages yet available. For the Austronesian languages, see Senft (141), supplemented by Barnes (4), Fox (45), and Toren (154). For the Himalayan region, see B Bickel \& M Gaenszle (in preparation). The circumpolar cultures would also promise a rich comparative project (44). For particular cultures, see work on the Navajo, where there is excellent spatial material $(50,132,173)$, and on Bali, where there is rich ethnography, and where Wassmann \& Dasen (161) have now done some of the linguistic and cognitive work.
} 
the way it coheres, is the spatialization of thought and language in a predominantly absolute frame of reference.

This field of research thus promises to yield a new kind of synthesis of cultural and social observations of many different kinds, from the details of ecological exploitation to the preference for object shapes, domestic architecture, cosmological systems, and kinesic patterns. It is a branch of cognitive anthropology that has been very much underexploited. In this review, I have attempted to make the more technical background accessible to the general reader, in the hope that its promise may be better appreciated and built upon.

\section{ACKNOWLEDGMENTS}

I am indebted to Elizabeth Keating, Gunter Senft, and David Wilkins for comments.

Any Annual Review chapter, as well as any article cited in an Annual Review chapter, may be purchased from the Annual Reviews Preprints and Reprints service. 1-800-347-8007; 415-259-5017; email: arpr@class.org

\section{Literature Cited}

1. Anderson S, Keenan E. 1985. Deixis. See Ref. 141a, pp. 259-307

2. Ardener S, ed. 1993. Women and Space: Ground Rules and Social Maps. Oxford: Berg

3. Baayen H, Danziger E, eds. 1994. Annual Report of the MPI for Psycholinguistics 1993. Nijmegen: Max Planck Inst. Psycholinguist.

4. Barnes RH. 1993. Everyday space: some considerations on the representation and use of space in Indonesia. In Altagswissen, ed. J Wassmann, P Dasen, pp. 159-80. Freiburg: Universitätsverlag

5. Berry JW, Irvine SH, Hunt EB. 1988. Indigenous Cognition: Functioning in Cultural Context. Dordrecht: Nijhoff

6. Bickel B. 1996. Spatial operations in deixis, cognition, and culture: where to ori- ent oneself in Belhare. In With Language in Mind: The Relationship Between Linguistic and Conceptual Representation, ed. J Nuyts, E Pederson. Cambridge: Cambridge Univ. Press

7. Bierwisch M, Lang E, eds. 1989. Dimensional Adjectives: Grammatical Structure and Conceptual Interpretation. Berlin: Springer-Verlag

8. Bourdieu P. 1977. Outline of a Theory of Practice. Cambridge: Cambridge Univ. Press

9. Bowerman M. 1996. The origins of children's spatial semantic categories: cognitive versus linguistic determinants. See Ref. 51, pp. 145-76

10. Bowerman M, de León L, Choi S. 1995. Verbs, particles, and spatial semantics: learning to talk about spatial actions in 
topologically different languages. In Proc. 27th Annu. Child Lang. Res. Forum, ed. EV Clark, pp. 101-10, Stanford, CA: CSLI

11. Bowerman M, Levinson SC, eds. 1996. Language acquisition and conceptual development. Cambridge: Cambridge Univ. Press

12. Bowerman M, Pederson E. 1992. Crosslinguistic perspectives on topological spatial relations. Presented at Annu. Meet. Am. Anthropol. Assoc., 91st, San Francisco

13. Brown P. 1991. Spatial conceptualization in Tzeltal. Work. Pap. No. 6, Cogn. Anthropol. Res. Group, Nijmegen

14. Brown P. 1993. The role of shape in the acquisition of Tzeltal locatives: a preliminary report. In Proc. 25th Child Lang. Res. Forum, ed. EV Clark, pp. 211-20. Stanford, CA: CSLI/Univ. Chicago Press

15. Brown P. 1994. The INs and ONs of Tzeltal locative expressions: the semantics of static descriptions of location. See Ref. 62, pp. $743-90$

16. Brown P, Levinson SC. 1992. 'Left' and 'right' in Tenejapa: investigating a linguistic and conceptual gap. See Ref. 31, pp. 590-611

17. Brown P, Levinson SC. 1993. "Uphill" and "downhill" in Tzeltal. J. Linguist. Anthropol. 3(1):46-74

18. Brown P, Levinson SC. 1993. Linguistic and nonlinguistic coding of spatial arrays: explorations in Mayan cognition. Work. Pap. No. 24, Cogn. Anthropol. Res. Group, Nijmegen

19. Brugman C. 1983. The use of body-part terms as locatives in Chalcatongo Mixtec. Surv. Calif. Other Indian Lang. 4:235-90

20. Carlson-Radvansky LA, Irwin DA. 1993. Frames of reference in vision and language: Where is above? Cognition 46:223-44

21. Casey ES. 1993. Getting Back into Place: Toward a Renewed Understanding of the Place-World. Bloomington: Indiana Univ. Press

22. Cavalli-Sforza L, Piazza A, Menozzi P, Mountain J. 1988. Reconstruction of human evolution: bringing together genetic, archaeological and linguistic data. Proc. Natl. Acad. Sci. USA 85(16):6002-6

23. Choi S, Bowerman M. 1991. Learning to express motion events in English and Korean: the influence of language-specific lexicalization patterns. Cognition 41: 83-121

24. Clark HH. 1973. Space, time, semantics, and the child. In Cognitive Development and the Acquisition of Language, ed. TE Moore, pp. 28-64. New York: Academic

25. Danziger E. 1993. Review of Perkins:
"Deixis, Grammar and Culture." Linguistics 31:977-80

26. Danziger E. 1994. Out of sight, out of mind: person, perception and function in Mopan Maya spatial deixis. See Ref. 62, pp. 885-907

27. Danziger E. 1996. Parts and their counterparts: social and spatial relationships among the Mopan Maya. J. R. Anthropol. Inst. Man 2(1):67-82

28. de León L. 1993. Shape, geometry and location: the case of Tzotzil body part terms. In CLS 29: Papers from the Parasession on Conceptual Representations, ed. K Beals, G Cooke, D Kathman, S Kita, KE McCullough, et al, pp. 77-90. Chicago: Univ. Chicago Press

29. de León L. 1994. Explorations in the acquisition of location and trajectory in Tzotzil. See Ref. 62, pp. 857-84

30. de León L. 1996. The development of geocentric location in young speakers of Guugu Yimithirr. Work. Pap. No. 33, Cogn. Anthropol. Res. Group, Nijmegen

31. de León L, Levinson SC, eds. 1992. Space in Mesoamerican languages. Z. Phon. Sprachwiss. Kommun.forsch. 45(6): 57089. Berlin: Akademie Verlag

32. Denny JP. 1978. Locating the universals in lexical systems for spatial deixis. In $C L S$ 14: Papers from the Parasession on the Lexicon, ed. D Farkas, WM Jacobsen, KW Todrys, pp. 71-84. Chicago: Univ. Chicago Press

33. Denny JP. 1988. Contextualization and differentiation in cross-cultural cognition. See Ref. 5, pp. 213-29

34. Descola P. 1994. In the Society of Nature: A Native Ecology in Amazonia. Cambridge: Cambridge Univ. Press

35. Duranti A. 1994. From Grammar to Politics. Berkeley: Univ. Calif. Press

36. Durkheim E, Mauss M. 1963/1903. Primitive Classification, ed./transl. R Needham. Chicago: Univ. Chicago Press (From French)

37. Earman J. 1989. World Enough and SpaceTime: Absolute Versus Relational Theories of Space and Time. Cambridge, MA: MIT Press

38. Eilan N, McCarthy R, Brewer B, eds. 1993. Spatial Representation: Problems in Philosophy and Psychology. Oxford: Blackwell

39. Evans N. 1995. A Grammar of Kayardild. Berlin: Mouton Grammar Libr.

40. Feinberg R. 1988. Polynesian Seafaring and Navigation. Kent, $\mathrm{OH}$ : Kent State Univ. Press

41. Fillmore C. 1975. Santa Cruz Lectures on Deixis. Mimeo, Indiana Univ. Linguist. Club

42. Fillmore C. 1982. Towards a descriptive 
framework for spatial deixis. See Ref. 75, pp. 31-60

43. Foley WA. 1986. The Papuan Languages of New Guinea. Cambridge: Cambridge Univ. Press

44. Fortescue M. 1988. Eskimo orientation systems. Medd. Grønl.: Man Soc. 11:3-30

45. Fox J, ed. 1993. Inside Austronesian houses. Canberra: Aust. Nat. Univ. Press

46. Frake C. 1985. Cognitive maps of time and tide among medieval seafarers. Man (NS) 20:254-70

47. Freidel D, Schele L, Parker J. 1993. Maya Cosmos. New York: Morrow

48. Goddard C, Wierzbicka A, eds. 1994. Semantic and Lexical Universals. Amsterdam, Philadelphia: Benjamins

49. Goodwin C. 1981. Conversational Organization: Interaction Between Speakers and Hearers. New York: Academic

50. Griffin-Pierce T. 1992. Earth Is My Mother, Sky Is My Father: Space, Time and Astronomy in Navajo Sandpainting. Albuquerque: Univ. N. M. Press

51. Gumperz JJ, Levinson SC, eds. 1996. Rethinking Linguistic Relativity. Cambridge: Cambridge Univ. Press

52. Hallpike CR. 1979. Foundations of Primitive Thought. Oxford: Clarendon

53. Hanks W. 1990. Referential Practice: Language and Lived Space in a Maya Community. Chicago: Univ. Chicago Press

54. Hanks W. 1996. Language form and communicative practices. See Ref. 51, pp. 232-70

55. Harkins J, Wilkins DP. 1994. Mparntwe Arrernte and the search for lexical universals. See Ref. 48, pp. 285-310

56. Harley JB, Woodward D, eds. 1987. The History of Cartography, 3 Vols. Chicago: Univ. Chicago Press

57. Haviland JB. 1979. Guugu Yimidhirr. In Handbook of Australian Languages, ed. RMW Dixon, B Blake, pp. 27-182. Canberra: Aust. Nat. Univ. Press

58. Haviland JB. 1991. The grammaticalization of motion (and time) in Tzotzil. Work. Pap. No. 2, Cogn. Anthropol. Res. Group, Nijmegen

59. Haviland JB. 1993. Anchoring, iconicity and orientation in Guugu Yimithirr pointing gestures. J. Linguist. Anthropol. 3(1):3-45

60. Haviland JB. 1996. Projections, transpositions, and relativity. See Ref. 51, pp. 269-323

61. Haviland JB. 1996. Guugu Yimithirr cardinal directions. In My Space or Yours: Beyond the Individual in the Cognitive Study of Language, ed. E Danziger. Ethos: J. Soc. Psychol. Anthropol. In press

62. Haviland JB, Levinson SC, eds. 1994.
Space in Mayan Languages. Linguistics 32 $(4 / 5)$

63. Heine B. 1989. Adpositions in African languages. Linguist. Afr. 2:77-127

64. Heine B, Claudi U, Hünnemeyer F. 1991. Grammaticalization: A Conceptual Framework. Chicago: Univ. Chicago Press

65. Herskovits A. 1986. Language and Spatial Cognition: An Interdisciplinary Study of the Prepositions in English. Cambridge: Cambridge Univ. Press

66. Hertz R. 1960/1909. The pre-eminence of the right hand: a study in religious polarity. In 'Death' and 'the Right Hand,' ed./ transl. R Needham, C Needham, pp. 89113. London: Cohen \& West

67. Hill C. 1982. Up/down, front/back, left/ right: a contrastive study of Hausa and English. See Ref. 165, pp. 11-42

68. Hill JH, Mannheim B. 1992. Language and world view. Annu. Rev. Anthropol. 21: 381-406

69. Hirsch E, O'Hanlon M, eds. 1995. The Anthropology of Landscape. Oxford: Clarendon

70. Hugh-Jones S. 1979. The Palm and the Pleiades: Ritual and Cosmology in Northwest Amazonia. Cambridge: Cambridge Univ. Press

71. Hunn E. 1993. Columbia Plateau Indian place names: what can they teach us? $J$. Linguist. Anthropol. 6(1):3-26

72. Hutchins E. 1983. Understanding Micronesian navigation. In Mental Models, ed. D Gentner, A Stevens, pp. 191-225. Hillsdale, NJ: Erlbaum

73. Jacobson SA. 1984. Semantics and morphology of demonstratives in Central Yupík Eskimo. Etudes/Inuit/Stud. 8:185-92

74. Jammer M. 1954. Concepts of Space: The History of Theories of Space in Physics. Cambridge, MA: Harvard Univ. Press

75. Jarvella R, Klein W, eds. 1982. Speech, Place and Action: Studies in Deixis and Related Topics. New York: Wiley

76. Jeannerod M. 1988. The Neural and Behavioural Organisation of Goal-Directed Movements. Oxford: Clarendon

77. Johnston JR, Slobin D. 1978. The development of locative expressions in English, Italian, Serbo-Croatian and Turkish. $J$. Child Lang. 6:529-45

78. Kant I. 1991/1768. Von dem ersten Grunde des Unterschiedes der Gegenden im Raume [On the first ground of the distinction of regions in space]. In The Philosophy of Right and Left: Incongruent Counterparts and the Nature of Space, ed./transl. J Van Cleve, RE Frederick, pp. 27-34. Dordrecht: Kluwer

79. Kari J. 1989. Some principles of Alaskan Athabaskan toponymic knowledge. In 
General and Amerindian Ethnolinguistics, ed. MR Key, H Hoenigswald, pp. 129-50. Berlin: Mouton

80. Kay P. 1977. Language evolution and speech style. In Sociocultural Dimensions of Language Change, ed. B Blount, M Sanchez, pp. 21-34. New York: Academic

81. Keating E. 1995. Spatial conceptions of social hierarchy in Pohnpei, Micronesia. In Spatial Information Theory: Theoretical Basis for GIS, ed. AU Frank, W Kuhn, pp. 463-74. Berlin: Springer-Verlag

82. Keating E. 1995. Power sharing: language, rank, gender and social space in Pohnpei, Micronesia. PhD thesis. Univ. Calif., Los Angeles. 310 pp.

83. Keating E. 1996. The social valuing of left and right in Pohnpei: linking status, space and cognition. Work. Pap. No. 35, Cogn. Anthropol. Res. Group, Nijmegen

84. Kendon A. 1988. Sign Languages of Aboriginal Australia. Cambridge: Cambridge Univ. Press

85. Kendon A. 1991. Conducting Interaction. Cambridge: Cambridge Univ. Press

86. Klich LZ. 1983. Re-directions in cognitive research with Australian Aborigines. Aust. Aborig. Stud. 1:38-42

87. Lahiri TK. 1965. Tracking techniques of Australian Aborigines. Canberra: Aust. Inst. Aborig./Torres Strait Islander Stud.

88. Lakoff G. 1987. Women, Fire and Other Dangerous Things. Chicago: Univ. Chicago Press

89. Landau B, Jackendoff R. 1993. "What" and "where" in spatial language and spatial cognition. Behav. Brain Sci. 16:217-65

90. Lang E. 1995. Basic dimension terms: a first look at universal features and typological variation. Forsch.schwerpkt. Allg. Sprachwiss. Work. Pap. No. 1, Berlin

91. Laughren M. 1978. Directional terminology in Warlpiri. Work. Pap. Lang. Linguist., 1:1-16. Launceston, Aust: Tasman. Coll. Adv. Educ.

92. Lawrence DL, Low SM. 1990. The built environment and spatial form. Annu. Rev. Anthropol. 19:453-505

93. Leer J. 1989. Directional systems in Atha baskan and Na-Dene. In Trends in Linguistics, ed. E Cook, KD Rice, 15:575-622. Berlin: Mouton

94. Levelt WJM. 1984. Some perceptual limitations on talking about space. In Limits in Perception, ed. AJ van Doorn, WA van der Grind, JJ Koenderink, pp. 323-58. Utrecht: Ver. Ned. Uitg. Sci. Press

95. Levelt WJM. 1996. Perspective taking and ellipsis in spatial descriptions. In Language and Space, ed. P Bloom, M Peterson, L Nadel, M Garrett. Cambridge, MA: MIT Press

96. Levine SC, Carey S. 1982. Up front: the ac- quisition of a concept and a word. J. Child Lang. 9:645-57

97. Levinson SC. 1983. Pragmatics. Cambridge: Cambridge Univ. Press

98. Levinson SC. 1992. Primer for the field investigation of spatial description and conception. Pragmatics 2(1):5-47

99. Levinson SC. 1992. Language and cognition: cognitive consequences of spatial description in Guugu Yimithirr. Work. Pap. No. 13, Cogn. Anthropol. Res. Group, Nijmegen

100. Levinson SC. 1994. Vision, shape and linguistic description: Tzeltal body-part terminology and object description. See Ref. 62, pp. 791-855

101. Levinson SC. 1994. Deixis. In Encyclopedia of Language and Linguistics, ed. RE Asher, 2:853-57. Oxford: Pergamon

102. Levinson SC. 1996. Frames of reference and Molyneux's question: cross-linguistic evidence. In Language and Space, ed. $\mathrm{P}$ Bloom, M Peterson, L Nadel, M. Garrett. Cambridge, MA: MIT Press

103. Levinson SC. 1996. Relativity in spatial conception and description. See Ref. 51

104. Levinson SC. 1996. Studying Spatial Conceptualization across Cultures. In $M y$ Space or Yours: Beyond the Individual in the Cognitive Study of Language, ed. E Danziger. Ethos: J. Soc. Psychol. Anthropol. In press

105. Levinson SC, Brown P. 1994. Immanuel Kant among the Tenejapans: anthropology as empirical philosophy. Ethos 22(1):3-41

106. Levy P. 1994. How shape becomes grammar: on the semantics of part morphemes in Totonac. Work. Pap. No. 29, Cogn. Anthropol. Res. Group, Nijmegen

107. Lewis D. 1976. Observations on route finding and spatial orientation among the aboriginal peoples of the Western Desert Region of Central Australia. Oceania 46(4): 249-82

108. Lewis D. 1976. Route finding by desert aborigines in Australia. J. Navig. 29:21-38

109. Littlejohn J. 1960. The Temne house. Sierra Leone Stud. 14:63-79

110. Lyons J. 1977. Semantics, Vols. 1, 2. Cambridge: Cambridge Univ. Press

111. MacLaury R. 1989. Zapotec body-part locatives: prototypes and metaphoric extensions. Int. J. Am. Linguist. 55(2):119-54

112. Marr D. 1982. Vision. New York: Freeman

113. McCarthy R. 1993. Assembling routines and addressing representations: an alternative conceptualization of 'what' and 'where' in the human brain. See Ref. 38, pp. 373-99

114. Miller G, Johnson-Laird PN. 1976. Language and Perception. Cambridge, MA: Harvard Univ. Press 
115. Moore H. 1986. Space, Text and Gender: An Anthropological Study of the Marakwet of Kenya. Cambridge: Cambridge Univ. Press

116. Munn N. 1986. Walbiri Iconography. Ithaca, NY: Cornell Univ. Press

117. Myers F. 1986. Pintupi Country, Pintupi Self. Canberra: Aust. Inst. Aborig. Torres Strait Isl. Stud.

118. Nash D. 1993. Notes on way-finding in Australia's deserts by Warlpiri and their neighbours. Presented at Conf. Spat. Represent., Max Planck Inst. Psycholinguist., Nijmegen

119. Needham R. 1973. Left and Right. Chicago: Univ. Chicago Press

120. Nichols J. 1992. Linguistic Diversity in Space and Time. Chicago: Univ. Chicago Press

121. Ochs E. 1996. Linguistic resources for socializing humanity. See Ref. 51, pp. 407-37

122. O'Keefe J. 1993. Kant and the sea-horse: an essay in the neurophilosophy of space. See Ref. 38, pp. 43-64

123. O'Keefe J, Nadel L. 1978. The Hippocampus as a Cognitive Map. Oxford: Clarendon

124. Ozanne-Rivierre F. 1987. L'expression linguistique de l'espace: quelques exemples oceaniens. Cah. Lacito 2:129-55

125. Paillard J, ed. 1991. Brain and Space. Oxford: Oxford Sci.

126. Pederson E. 1993. Geographic and manipulable space in two Tamil linguistic systems. In Spatial Information Theory, ed. AU Frank, I Campari, pp. 294-311. Berlin: Springer-Verlag

127. Pederson E. 1995. Language as context, language as means: spatial cognition and habitual language use. Cogn. Linguist. 6(1):33-62

128. Pederson E. 1996. Review of S Svorou's "The grammar of space." In Sprachtypol. Universal.forsch. 49(2):37-41

129. Perkins RD. 1992. Deixis, Grammar and Culture. Amsterdam, Philadelphia: Benjamins

130. Piaget J, Inhelder B. 1956. The Child's Conception of Space. London: Routledge/ Kegan Paul

131. Pick HL Jr. 1993. Organization of spatial knowledge in children. See Ref. 38, pp. 31-42

132. Pinxten R, van Dooren I, Harvey F. 1983. Anthropology of Space: Explorations into the Natural Philosophy and Semantics of the Navajo. Philadelphia: Univ. Pa. Press

133. Poincaré H. 1946. The Foundations of Science. Transl. GB Halsted. Lancaster, PA: Science Press

134. Rapoport A. 1975. Australian aboriginals and the definition of place. In Shelter, Sign
\& Symbol, ed. P Oliver, pp. 38-51. London: Barrie \& Jenkins

135. Renfrew C. 1987. Archaeology and Language. Cambridge: Cambridge Univ. Press

136. Renfrew C, Zubrow EBW, eds. 1994. The Ancient Mind: Elements of Cognitive Archaeology. Cambridge: Cambridge Univ. Press

137. Rumsey A. 1994. The dreaming, human agency and inscriptive practice. Oceania 65:116-30

138. Schöne H. 1984. Spatial Orientation. Princeton, NJ: Princeton Univ. Press

139. Senft G. 1994. Ein Vorschlag, wie man standardisiert Daten zum Thema 'Sprache, Kognition und Konzeption des Raums' in verschiedenen Kulturen erheben kann. Linguist. Ber. 154:413-29

140. Senft G. 1995. Sprache, Kognition und Konzepte des Raumes in verschiedenen Kulturen. Kognitionswiss. 4:166-70

141. Senft G, ed. 1996. Classificatory Particles in Kilivila. Oxford: Oxford Univ. Press. $337 \mathrm{pp}$.

141a. Shopen T, ed. 1985. Language Typology and Syntactic Description, Vol. 3, Grammatical Categories and the Lexicon. Cambridge: Cambridge Univ. Press

142. Slobin DI. 1985. Cross-linguistic evidence for the language-making capacity. In The Cross-Linguistic Study of Language Acquisition, ed. DI Slobin, pp. 1157-256. Hillsdale, NJ: Erlbaum

143. Slobin DI. 1996. From "thought and language" to "thinking for speaking." See Ref. 51, pp. 70-96

144. Stein JF. 1992. The representation of egocentric space in the posterior parietal cortex. Behav. Brain Sci. 15(4):691-700

145. Stolz C. 1995. Spatial dimensions and orientation of objects in Yucatec Maya. $\mathrm{PhD}$ thesis. Univ. Bielefeld

146. Stross B. 1991. Classic Maya directional glyphs. J. Linguist. Anthropol. 1(1):97-114

147. Svorou S. 1994. The Grammar of Space. Amsterdam: Benjamins

148. Swain T. 1993. A Place for Strangers: Towards a History of Australian Aboriginal Being. Cambridge: Cambridge Univ. Press

149. Talmy L. 1983. How language structures space. In Spatial Orientation: Theory, Research and Application, ed. H Pick, L Acredolo, pp. 225-82. New York: Plenum

150. Talmy L. 1985. Lexicalization patterns: semantic structure in lexical forms. See Ref. $141 \mathrm{a}$, pp. $56-149$

151. Tambiah S. 1985. Culture, Thought and Social Action. Cambridge, MA: Harvard Univ. Press

152. Tilley C. 1994. A Phenomenology of Landscape: Places, Paths and Monuments. Oxford: Berg 
153. Tolman EC. 1948. Cognitive maps in rats and men. Psychol. Rev. 55(4):109-45

154. Toren C. 1990. Making Sense of Hierarchy: Cognition as Social Process in Fiji. London: Athlone

155. Tuan Y-F. 1977. Space and Place: The Perspective of Experience. Minneapolis: Univ. Minn. Press

156. Turnbull D. 1993. Maps Are Territories: Science Is an Atlas: A Portfolio of Exhibits. Chicago: Univ. Chicago Press

157. Ulltan R. 1978. Some general characteristics of interrogative systems. In Universals of Human Language, ed. J Greenberg, 4:211-48. Stanford, CA: Stanford Univ. Press

158. Ungerleider LG, Mishkin M. 1982. Two cortical visual systems. In Analysis of Visual Behavior, ed. DJ Ingle, MA Goodale, RJW Mansfield, pp. 549-86. Cambridge, MA: MIT Press

159. Van Cleve J, Frederick RE, eds. 1991. The Philosophy of Right and Left. Dordrecht: Kluwer

160. Vandeloise C. 1991. Spatial Prepositions: A Case Study from French. Chicago: Univ. Chicago Press

161. Wassmann J, Dasen P. 1996. Une combination de methodes ethnographiques et psychologiques dans l'étude des processus cognitifs à Bali. In Théorie et Pratique de l'Interculturel, ed. B Krewer. Paris: L'Harmattan. In press

162. Waterman TH. 1989. Animal Navigation. Sci. Am. Libr.

163. Waterson R. 1991. The Living House: An Anthropology of Architecture in South East Asia. Singapore: Oxford Univ. Press

164. Weiner JF. 1991. The Empty Space: Poetry, Space and Being Among the Foi of Papua New Guinea. Bloomington: Indiana Univ. Press

165. Weissenborn J, Klein W, eds. 1982. Here and There: Cross-Linguistic Studies on
Deixis and Demonstration. Amsterdam: Benjamins

166. Widlok T. 1994. The social relationships of changing Hai//om hunter/gatherers in northern Namibia, 1990-1994. PhD thesis. Univ. London

167. Wilkins D. 1991. The semantics, pragmatics and diachronic development of 'associated motion' in Mparnte Arrernte. Buffalo Pap. Linguist. 1:207-57

168. Wilkins D, Hill D. 1995. When 'GO' means 'COME': questioning the basicness of basic motion verbs. Cogn. Linguist. 6:209-59

169. Wilkins D, Senft G. 1994. A man, a tree, and forget about the pigs: space games, spatial reference and an attempt to identify functional equivalents across languages. Presented at 19th Linguist. Agency Univ. Duisburg Conf., Duisburg

170. Wilkins DP. 1989. Mparntwe Arrernte (Aranda): the structure and semantics of an Australian language. $\mathrm{PhD}$ thesis. Aust. Nat. Univ., Canberra. 621 pp.

171. Wilkins DP. 1996. Handsigns and hyperpolysemy: exploring the cultural foundations of semantic association. Pacific Linguistics. In press

172. Williams N, Baines G, eds. 1993. Traditional Ecological Knowledge. Canberra Cent. Resour. Environ. Stud., Aust. Nat. Univ.

173. Witherspoon G. 1992. Language and Art in the Navajo Universe. Ann Arbor: Univ. Mich. Press

174. Wolfowitz C. 1991. Language Style and Social Space: Stylistic Choice in Suriname Javanese. Urbana: Univ. Ill. Press

175. Wynn T. 1989. The Evolution of Spatial Competence. Urbana-Champaign: Univ. Ill. Press

176. Yates FA. 1966. The Art of Memory. Chicago: Univ. Chicago Press 